\title{
Schizencephaly revisited
}

\author{
Paul D. Griffiths ${ }^{1}$
}

Received: 1 May 2018 / Accepted: 9 July 2018 / Published online: 19 July 2018

(C) The Author(s) 2018

\begin{abstract}
Purpose In this paper, I will report the range of appearances of schizencephaly in children and fetuses by reviewing a 10-year experience from a single centre and detail classification systems for the different forms of schizencephaly. This will lead to reassessment of possible aetiological and mechanistic causes of schizencephaly.

Methods All cases of pediatric and fetal schizencephaly were located on the local database between 2007 and 2016 inclusive. The studies were reviewed for the presence, location and type of schizencephaly, as well as the state of the (cavum) septum pellucidum, the location of the fornices and the presence of other brain abnormalities.

Results The review included 21 children and 11 fetuses with schizencephaly. Schizencephaly (type 1) was found in $9 \%$ of children but no fetuses, schizencephaly (type 2) was present in $67 \%$ of the pediatric cases and in $45 \%$ of fetuses, whilst schizencephaly (type 3 ) was present in approximately $24 \%$ of children and $55 \%$ of fetuses. Other brain abnormalities were found in $67 \%$ of children and $55 \%$ of fetuses.

Conclusion I have proposed a new system for classifying schizencephaly that takes into account all definitions of the abnormality in the literature. Using that approach, I have described the appearances and associations of pediatric and fetal cases of schizencephaly from a single centre. Review of the current literature appears to favour an acquired destructive aetiology for most cases of schizencephaly, and I have proposed a mechanism to explain the cortical formation abnormalities found consistently in and around areas of schizencephaly.
\end{abstract}

Keywords MR imaging $\cdot$ Schizencephaly $\cdot$ Pediatric $\cdot$ Fetus

\section{Introduction}

Schizencephaly is a rare congenital abnormality of the brain that has a prevalence of approximately 1.5 per 100,000 live-born babies as estimated from a review of four million births in California [1]. Howe and colleagues reported a combined live birth/stillbirth rate of 1.48 per 100,000 from a population of over 2.5 million in the UK and less than half of those cases were detected antenatally [2]. In spite of recent interest in a range of genetic abnormalities that are associated with schizencephaly [3-5], the majority of cases of schizencephaly are sporadic and nonfamilial, and in most cases, an aetiological cause is not found [6].

Paul D. Griffiths

p.griffiths@sheffield.ac.uk

1 Academic Unit of Radiology, University of Sheffield, Floor C, Glossop Road, Sheffield, England S10 2JF, UK
Magnetic resonance (MR) imaging is central to the diagnosis of children with congenital brain abnormalities, and in utero MR (iuMR) imaging is now used for antenatal detection of brain abnormalities, including schizencephaly. The primary purpose of this paper is to assess the range of appearances of schizencephaly in children and fetuses by review of a 10 -year experience from a single centre. I will also detail the classification systems used to describe different forms of schizencephaly and re-consider the possible aetiological/ mechanistic causes.

\section{Methods}

\section{Definition}

There is a range of opinion about the definition of schizencephaly; specifically, some authorities consider a CSF-containing cleft running from the pial to the ependymal surfaces to be the sine qua non of schizencephaly [7-9]. In contrast, the definition of schizencephaly recently put forward 
Fig. 1 Classification of the three different types of schizencephaly used in this paper compared with other nomenclature systems with pictorial examples (see text for details)

Fig. 2 A child with porencephaly. MR imaging of an 8-year-old child with spastic quadriplegic cerebral palsy recognised in the first year of life. Axial T2weighted (a), axial FLAIR (b), coronal FLAIR (c) and coronal inversion recovery (d) show bilateral clefts involving the paracentral lobules, which extend from the outer surface of the brain but do not quite reach the ventricular margin. Some of the white matter next to the clefts is gliotic and there is no evidence of normal, or abnormal, grey matter lining the clefts. These features indicate porencephaly rather than schizencephaly

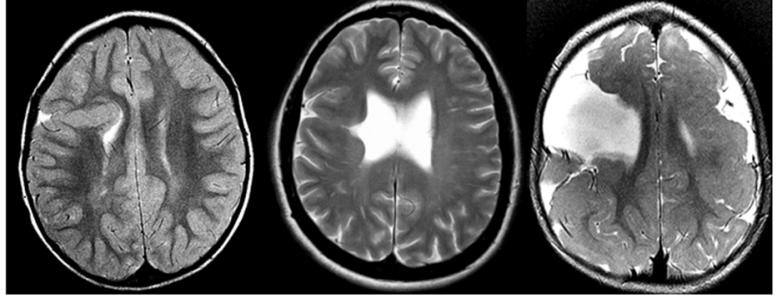

\begin{tabular}{|l|l|l|l|}
\hline Nomenclature used in this article & Schizencephaly & Schizencephaly & Schizencephaly \\
Nomenclature if a cleft is required for & Trans-mantle & Closed lip & Open lip \\
the diagnosis of schizencephaly & heterotopion & schizencephaly & schizencephaly \\
Nomenclature if a cleft is NOT & Closed lip & Open lip & Open lip \\
required for the diagnosis of & schizencephaly & schizencephaly & schizencephaly \\
\hline
\end{tabular}
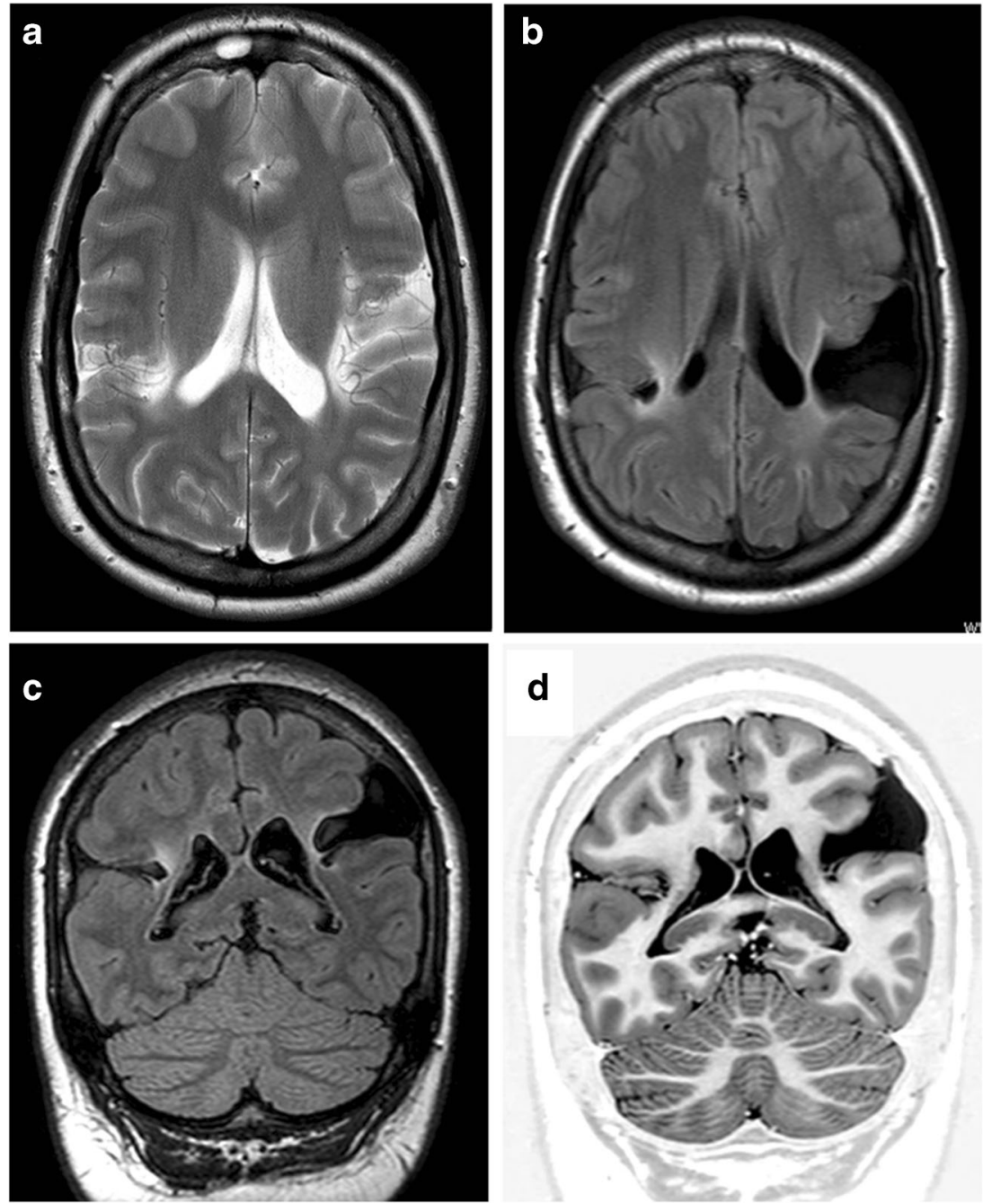


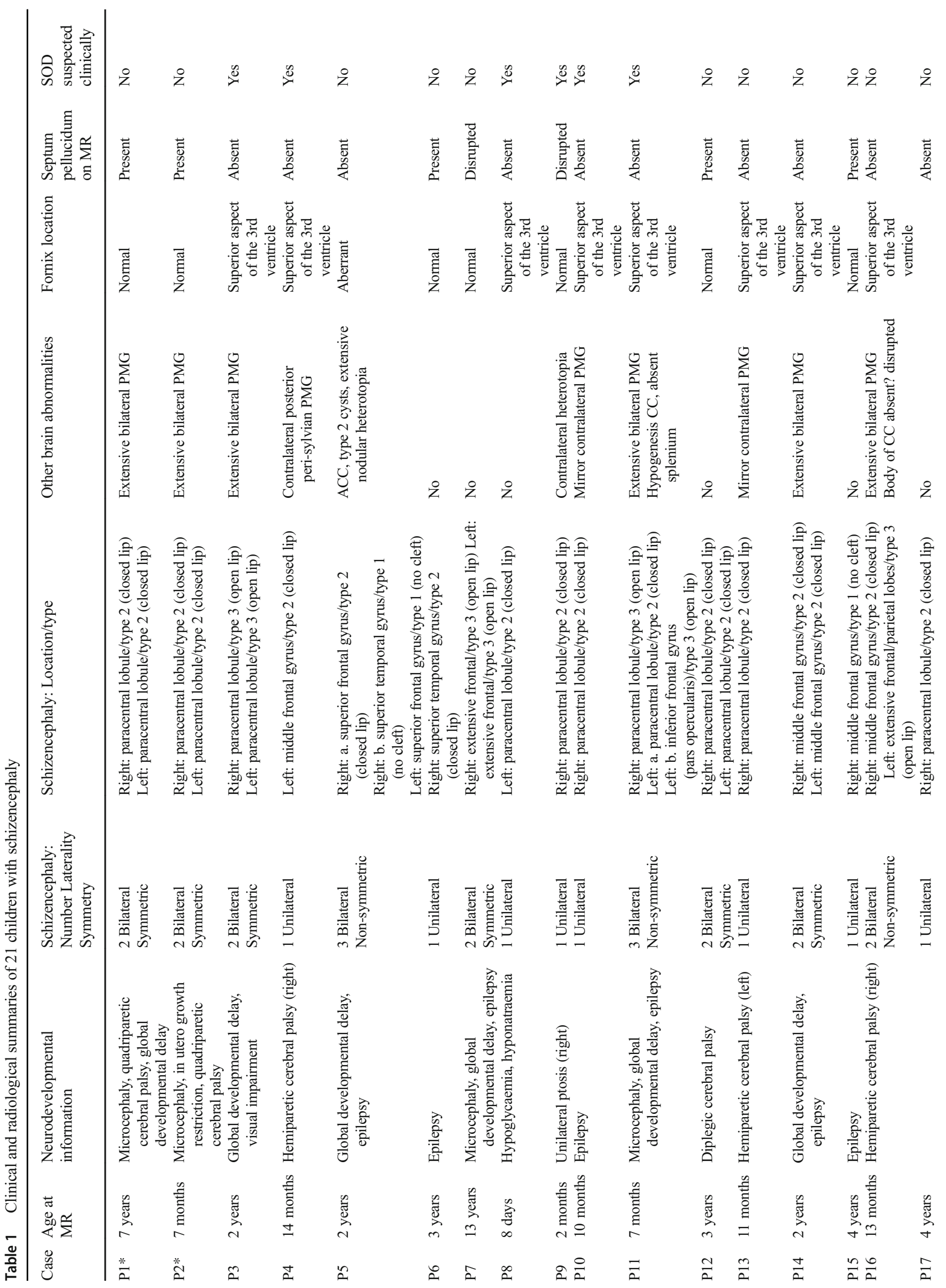




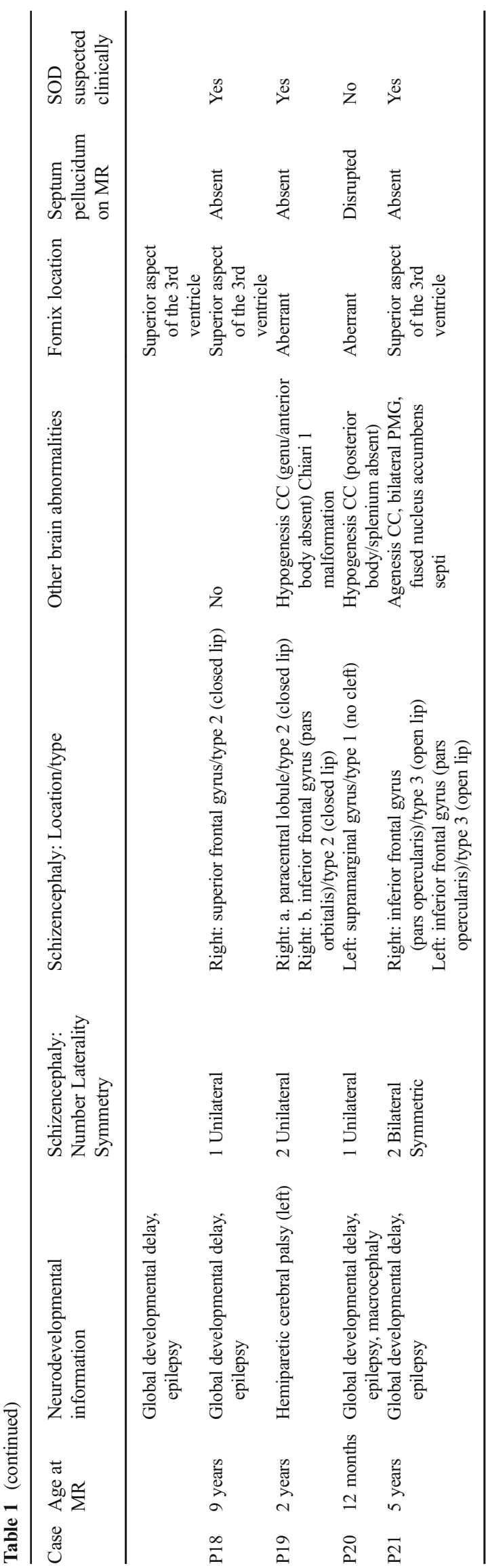

by Naidich et al. includes a trans-mantle column of dysplastic grey matter extending from the ependyma to the pia without a CSF cleft [10]. Those authors reference supportive evidence from the publications of Yakovlev and Wadsworth [11, 12] and specimens housed in the Yakovlev-Haalem collection at the Armed Forces Institute of Pathology, Washington, DC. The differences in nomenclature used by the two groups are summarised in Fig. 1 along with a unifying system that will be used in this article (below and Fig. 1).

Schizencephaly (type 1) - Trans-mantle column of abnormal grey matter but no evidence of a CSF-containing cleft on MR imaging

Schizencephaly (type 2) - CSF-containing cleft present, abutting lining lips of abnormal grey matter opposed Schizencephaly (type 3)-CSF-containing cleft present, non-abutting lining lips of abnormal grey matter

If two types of schizencephaly are present in the same individual, it is described in this paper by the numerically higher category; e.g. if a child has an open and a closed lip cleft, the individual will be classified as having schizencephaly (type 3 ). Figure 2 shows MR imaging from a child with porencephaly, the major differential diagnosis of schizencephaly and distinguished by the lack of abnormal grey matter lining the cleft.

\section{Caseload}

The cases of schizencephaly described in this paper are all from the Academic Unit of Radiology, University of Sheffield, and the MR imaging was performed between 2007 and 2016 inclusive. The local database was searched for all cases of schizencephaly reported on MR studies during that 10 -year period in children (aged 16 years or younger) and fetuses following in utero MR (iuMR) studies. All of the studies involving children and some of the iuMR studies were performed for clinical purposes, and the other iuMR studies were performed as part of research studies. The pregnant women recruited into research studies all provided written informed consent for the iuMR imaging if it was performed as a research study and, although they were not paid for their involvement, travel expenses were provided for the woman and a companion. Relevant review was sought, and approval obtained, from the Institutional Clinical Effectiveness Unit and Research Department in order to allow those cases performed for clinical purposes to be reported in this paper.

\section{MR imaging technique}

MR imaging for children was performed on either 1.5-T (Infinion, Philips Medical Systems, Cleveland, OH, or HDx 
Fig. 3 Unilateral schizencephaly (type 1). MR images of a 4-yearold child with focal epilepsy. Axial T2-weighted (a), right parasagittal T2-weighted (b), axial (c) and coronal reconstructions from $\mathrm{T} 1$ volume imaging show abnormal grey matter extending from ventricular to out surface of the brain, centred on the right middle frontal gyrus. No CSF cleft is visible, hence the classification as schizencephaly (type 1). The septum pellucidum is present and the course of the fornices is normal. No other brain abnormalities are present
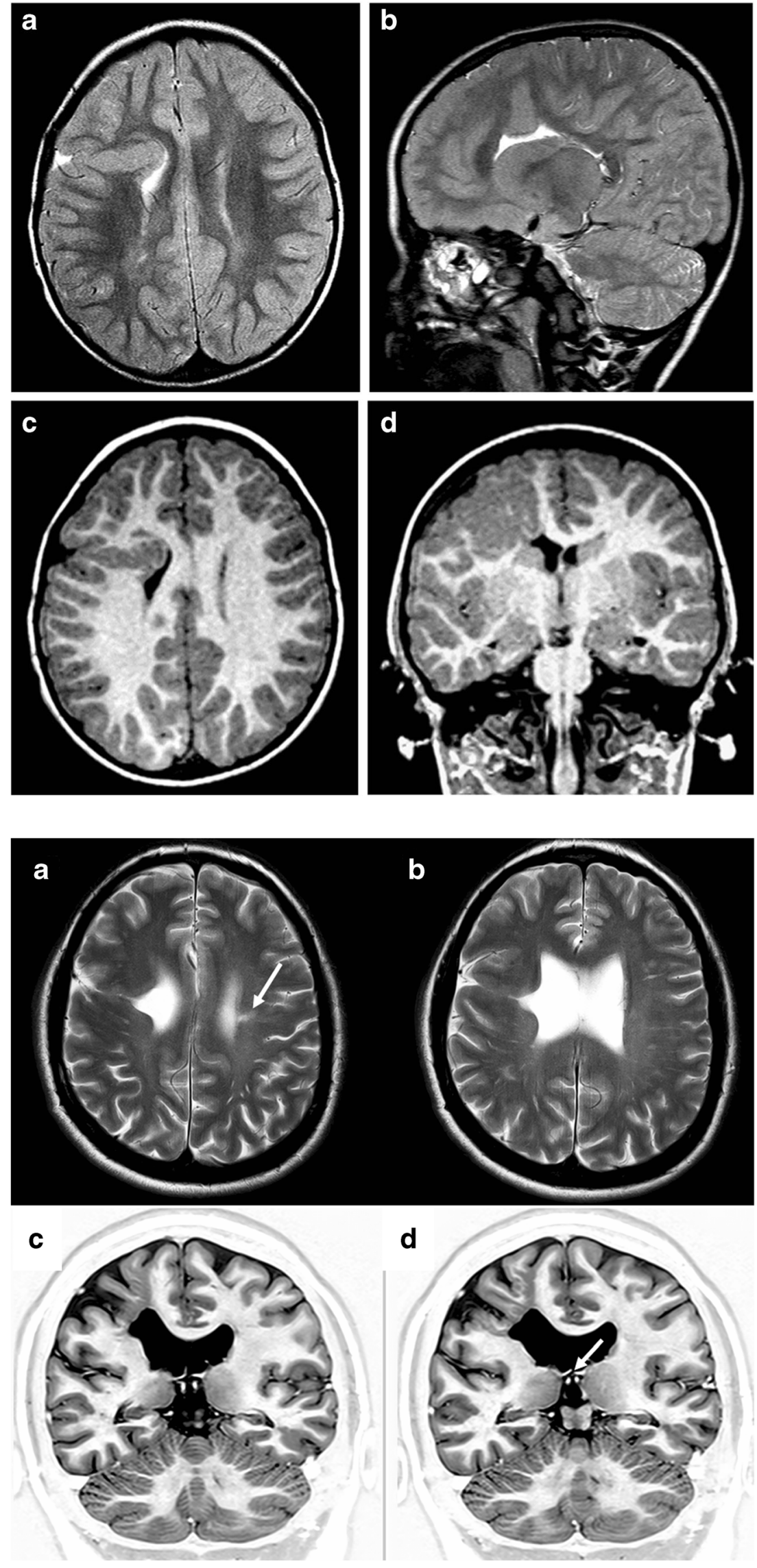

Fig. 4 Unilateral schizencephaly (type 2). MR images of a 4-yearold child with focal epilepsy and developmental delay. Axial T2weighted (a, b) and coronal inversion recovery $(\mathbf{c}, \mathbf{d})$ images show a CSF cleft with closely opposed borders lined with polymicrogyria. There is also a small area of gliosis in the white matter of the contralateral paracentral lobule (arrowed on a) The septum pellucidum is absent and the fornices lie abnormally low (arrowed on d). No other brain abnormalities were present 
Fig. 5 Bilateral schizencephaly (type 3). MR images of a 2-yearold child with global developmental delay. Axial T2weighted $(\mathbf{a}, \mathbf{b})$ and coronal reconstructions from T1weighted volume data $(\mathbf{c}-\mathbf{f})$ show bilateral CSF clefts with nonopposed borders lined with polymicrogyria. The septum pellucidum is absent and the fornices lie abnormally low (arrowed on $\mathbf{c}-\mathbf{f}$ ). Extensive cortical formation abnormalities were present in both hemispheres
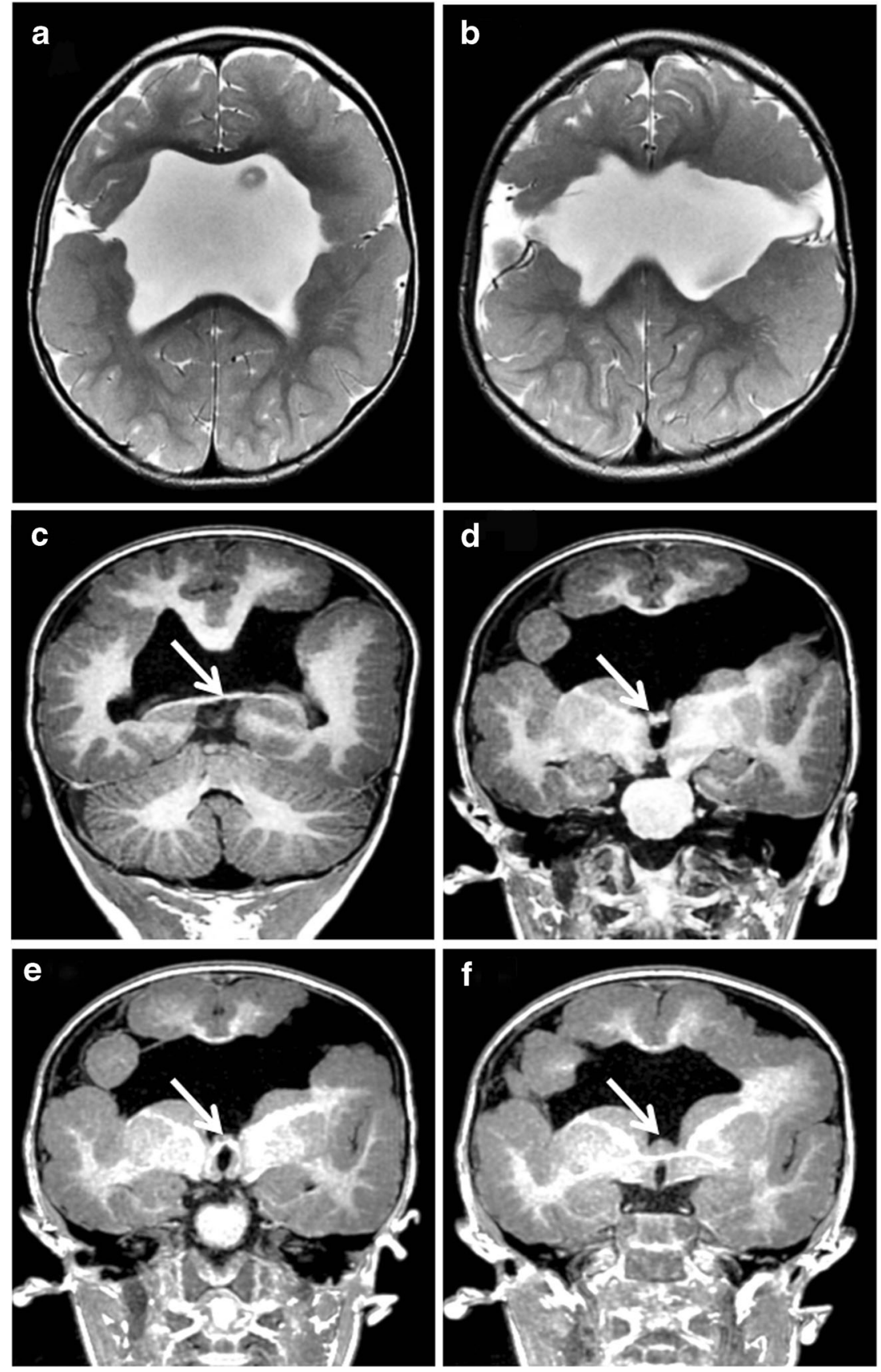

General Electric Healthcare, Milwaukee, WI) or 3.0-T MR scanners (Achieva, Philips Medical Systems, Best, Netherlands), whereas iuMR imaging was performed only on the 1.5-T scanners. The children in the study had the following MR sequences performed as a minimum: axial and coronal FSE T2-weighted, T1 volume imaging (1.5 mm partition thickness maximum), axial FLAIR and axial gradient echo T2* imaging. The iuMR studies consisted of ssFSE imaging in the three orthogonal planes $(5 \mathrm{~mm}$ thickness maximum), ultrafast axial T1 and axial diffusion-weighted imaging as a minimum. All fetuses imaged after 2013 had steady-state $3 \mathrm{D}$ volume imaging [13].

\section{Analysis}

All of the studies were reported clinically by a number of radiologists, but all of the studies were reviewed for the purposes of this paper by the author, an experienced pediatric neuroradiologist (over 25 years of pediatric neuroradiology and over 18 years of iuMR imaging experience). The presence, location and type of schizencephaly were recorded for each case as well as the condition of the (cavum) septum pellucidum, the location of the fornices and the presence of other brain abnormalities. 
Fig. 6 Two regions of schizencephaly (type 2) in the same hemisphere. MR images from a 2-year-old child with hemiparietic (left side of body) cerebral palsy. Axial T2-weighted image shows schizencephaly (type 2) related to the right paracentral lobule (arrowed on a) whilst the right parasagittal image from a $\mathrm{T} 1$ volume acquisition shows a further area of schizencephaly (type 2) in the inferior frontal gyrus (arrowed on b). The anterior part of the corpus callosum is absent and there is a low position of cerebellar tonsils. Coronal reconstructions from the $\mathrm{T} 1$ volume data from posterior to anterior (c-f) show an aberrant course of the fornices and distorted, thickened septum pellucidum (arrowed on $\mathbf{c}, \mathbf{e}$ and $\mathbf{f}$ )
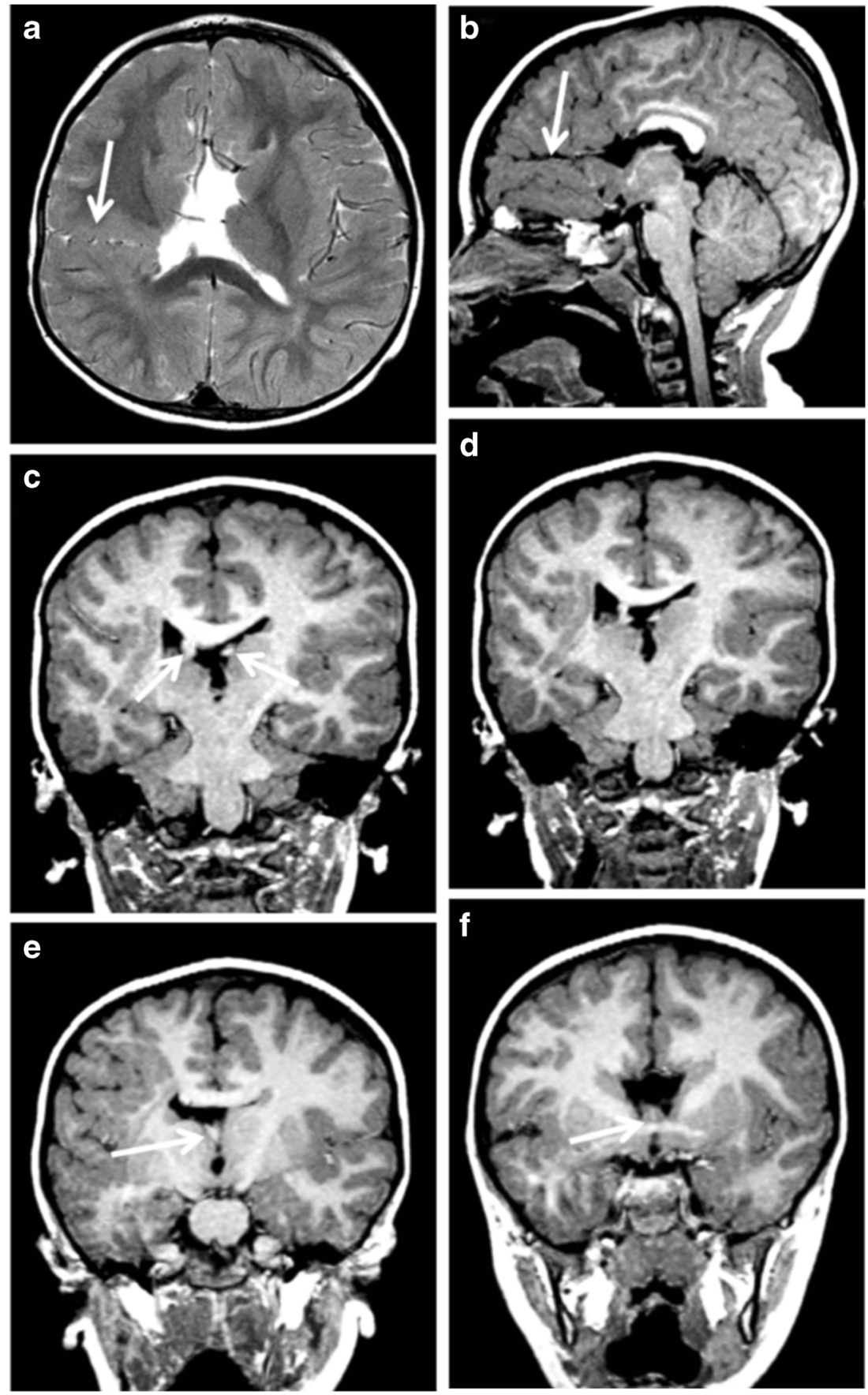

\section{Results}

\section{Pediatric cases}

Clinical and MR imaging summaries of 21 children with schizencephaly are shown in Table 1: 14/21 (67\%) pediatric cases in this series had schizencephaly (type 2), 5/21 (24\%) had schizencephaly (type 3), whilst schizencephaly (type 1) was present in only 2/21 (9\%). Examples are shown in Figs. 3, 4 and 5. Just under half had bilateral schizencephaly and 3/21 children had more than one cleft in a cerebral hemisphere (Fig. 6).

The septum pellucidum was present and intact in $5 / 21$ (24\%) of the pediatric cases (Fig. 7) and was absent in 13/21 $(62 \%)$ of children and disrupted in 3/21 (14\%) cases. The course of the fornices was normal [14] in all children with intact septum pellucidum, passing close to the splenium of the corpus callosum, suspended from the inferior margin of the septum pellucidum and showing the expected relationship with the anterior commissure at its termination (Figs. 3 and 7). 
Fig. 7 a-d Bilateral schizencephaly (type 2) with an intact septum pellucidum, normal course of the fornices, and no other brain abnormalities in a 3year-old child with diplegic cerebral palsy
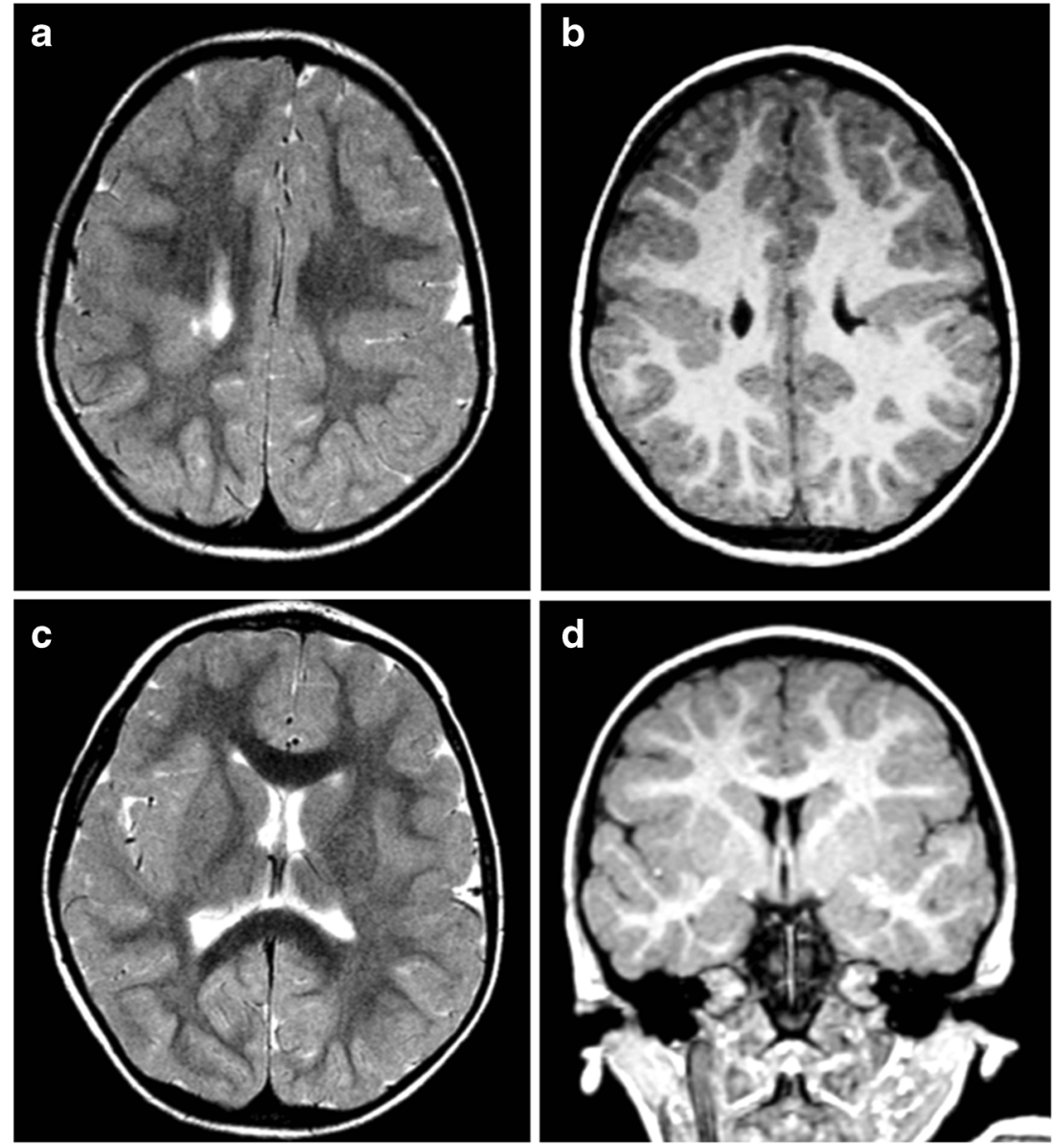

The course of the fornices was also normal in two thirds of the children with disrupted septum pellucidum. The fornices were present but sited abnormally low $[14,15]$ in $11 / 13$ children without a septum pellucidum (superior portion of the third ventricle-Figs. 4, 5 and 8). Three children (two with no septum pellucidum and one with a disrupted septum pellucidum) had an aberrant course of the fornices (Fig. 6) all of whom had failed commissuration, which probably accounted for the aberrant course [15].

Other brain abnormalities (not including the septum pellucidum/fornix or polymicrogyria localised to the vicinity of the cleft) were found in two thirds (14/21) of the children. Cortical formation abnormalities were the commonest, found in $12 / 21(57 \%)$ pediatric cases of which 10 were polymicrogyria. Failed commissuration was present in $5 / 21$ (24\%) pediatric cases - two cases of agenesis (Fig. 8) and three cases of hypogenesis of the corpus callosum. The two cases of known or suspected genetic causes are shown in Fig. 9.

\section{Fetal cases}

The iuMR imaging summaries of 11 fetuses with schizencephaly are shown in Table 2, and data comparing the findings in children and fetuses are presented in Table 3. Schizencephaly (type 2) was present in 5/11 (45\%) fetuses (Fig. 10) and schizencephaly (type 3) in 6/11 (55\%) fetuses (Fig. 11). No fetus had schizencephaly (type 1 ). Fetal head size $\leq 10$ th centile were found in $6 / 11$ cases, and in $4 / 11$, the head size was $<3$ rd centile, all of whom had schizencephaly (type 3). Unilateral schizencephaly was present in $7 / 11$ (64\%) and bilateral involvement in 4/11 (36\%). No fetus had multiple areas of schizencephaly in the same cerebral hemisphere.

The septum pellucidum was present and intact in 4/11 (36\%) fetuses (Fig. 10) and absent in 6/11 (55\%) fetuses (Fig. 11), and disrupted remnants of the septum pellucidum were shown in 1/11 (9\%). The path of the fornices was normal in all fetuses when the septum pellucidum was present or disrupted, whilst the fornices were abnormally low (superior portion of the third ventricle) in all cases of absent septum pellucidum.

Other brain abnormalities (not including the septum pellucidum/fornix) were found in 6/11 (55\%) fetuses-five had cortical formation abnormalities and the other fetus had focal encephalomalacia. Failed commissuration was not seen in any of these fetuses. 
Fig. 8 Bilateral schizencephaly (type 3) with multiple other brain abnormalities. MR imaging of a 5 -year-old child with global developmental delay and epilepsy. Coronal reconstructions from $\mathrm{T} 1$ volume datasets $(\mathbf{a}, \mathbf{b})$ show bilateral schizencephaly (type 3) involving the inferior frontal gyri. Bilateral cortical formation abnormalities are present in the superior portions of the frontal lobes. The corpus callosum and septum pellucidum are absent and the fornices have an abnormal low position (arrowed on $\mathbf{b}$ and $\mathbf{c}$ ). Axial T2weighted image shows abnormal fusion of the nucleus accumbens septi and basal forebrain across the midline (arrowed on d) which possibly represents a form of septo-preoptic holoprosencephaly
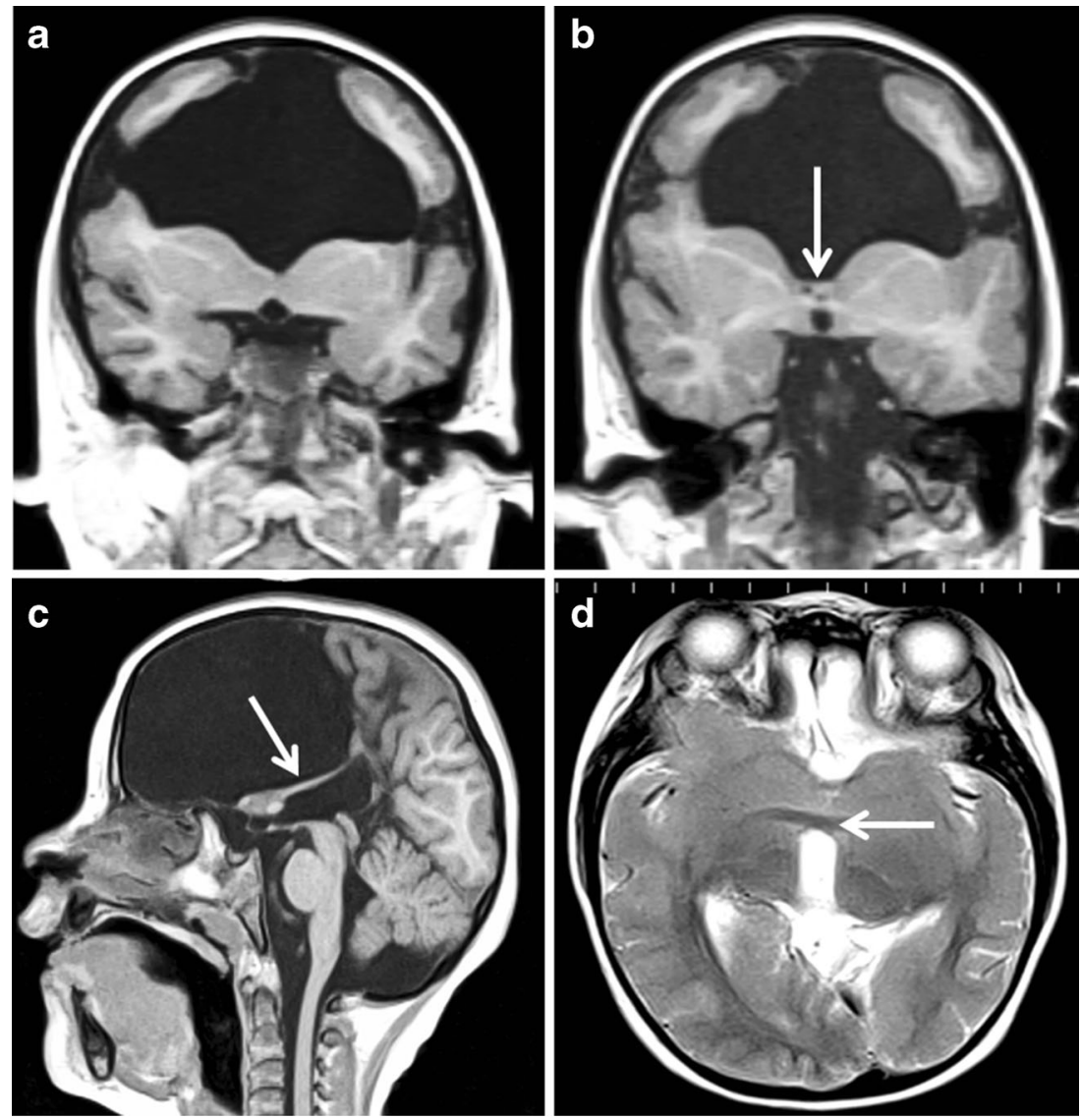

Fig. 9 MR images of a 7-year-old child (upper pane of the images) with bilateral schizencephaly (type 2) and known EMX2 genetic mutation and MR images of a 7-month-old child with a strong family history of schizencephaly but no genetic testing at the time of the MR study (lower pane of the images). The two cases show similar imaging features as discussed in the text

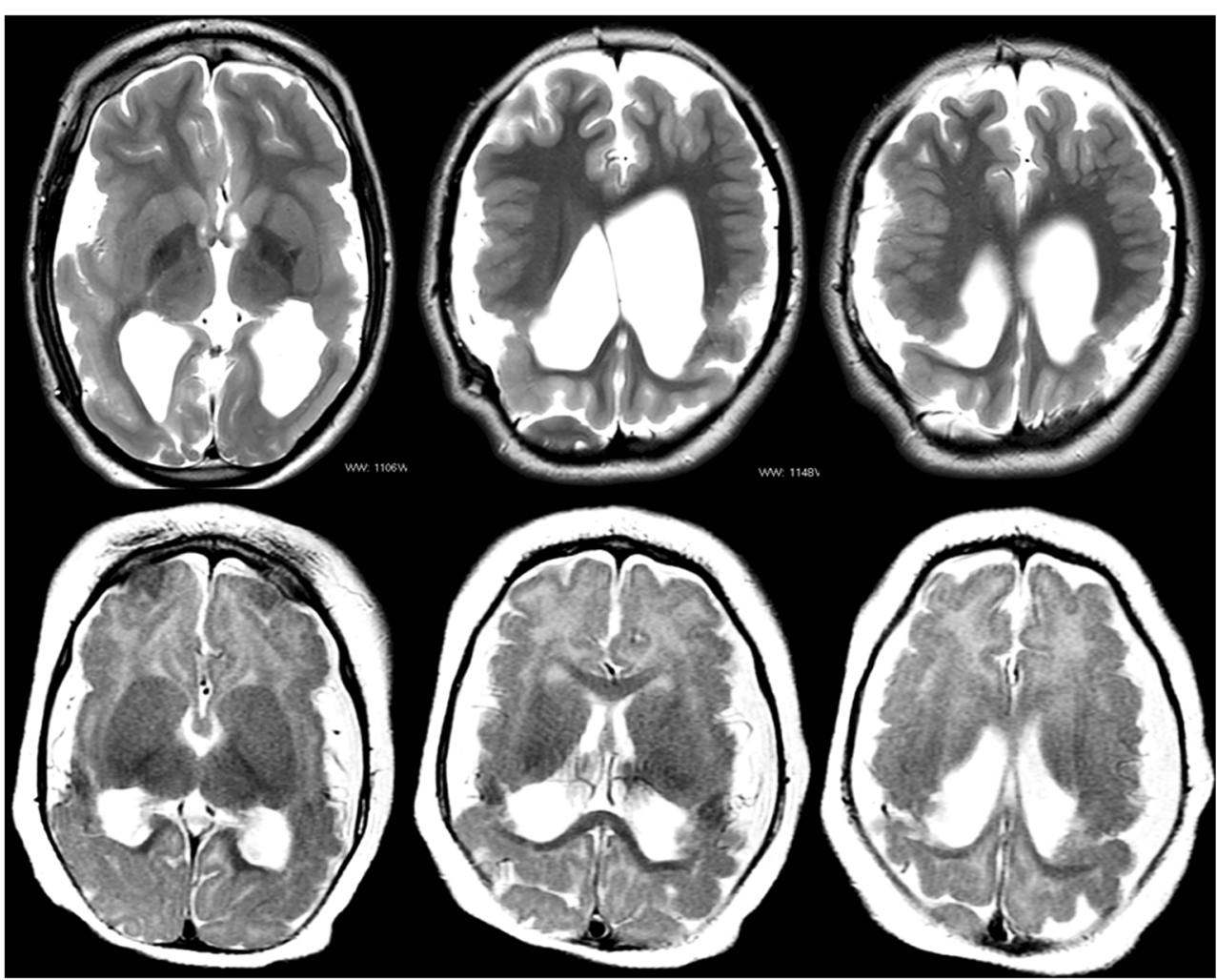




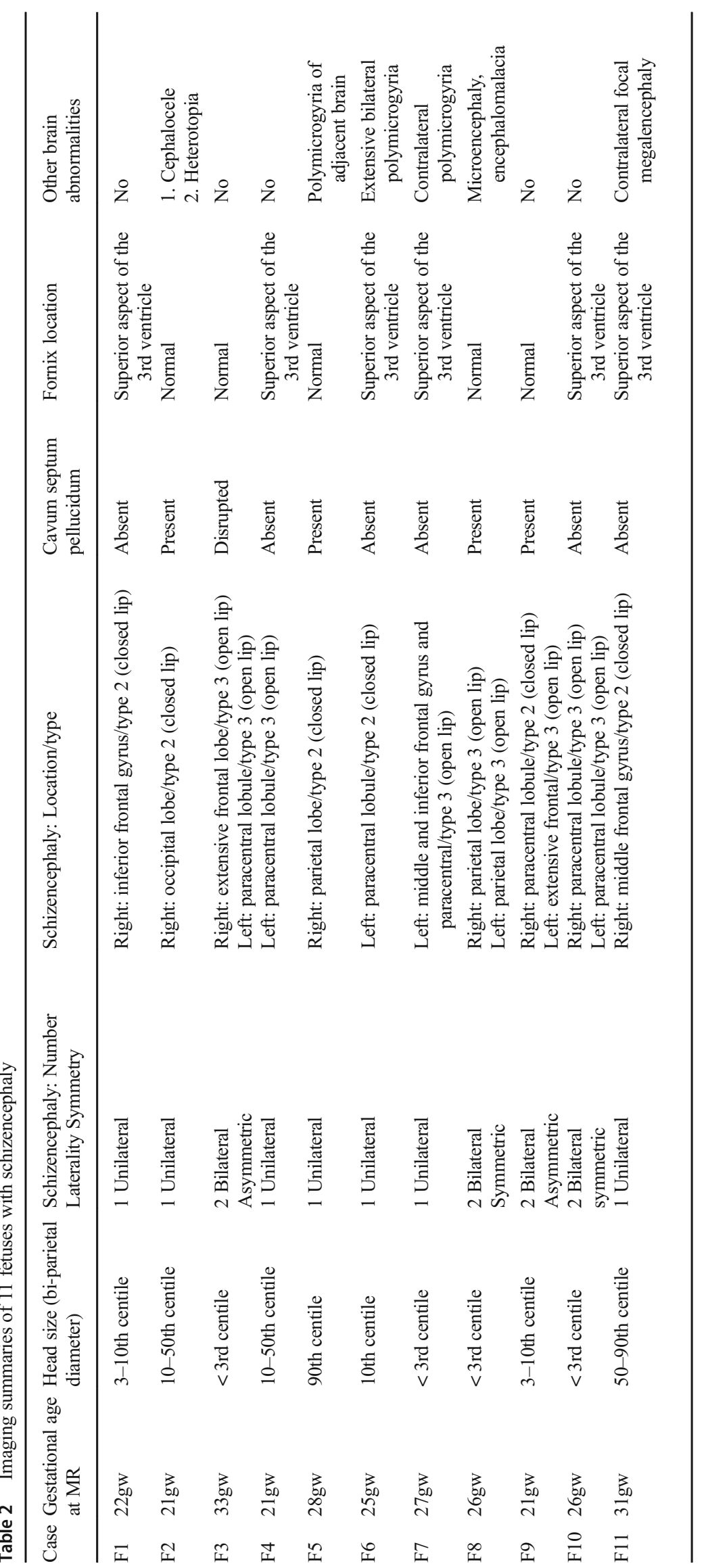




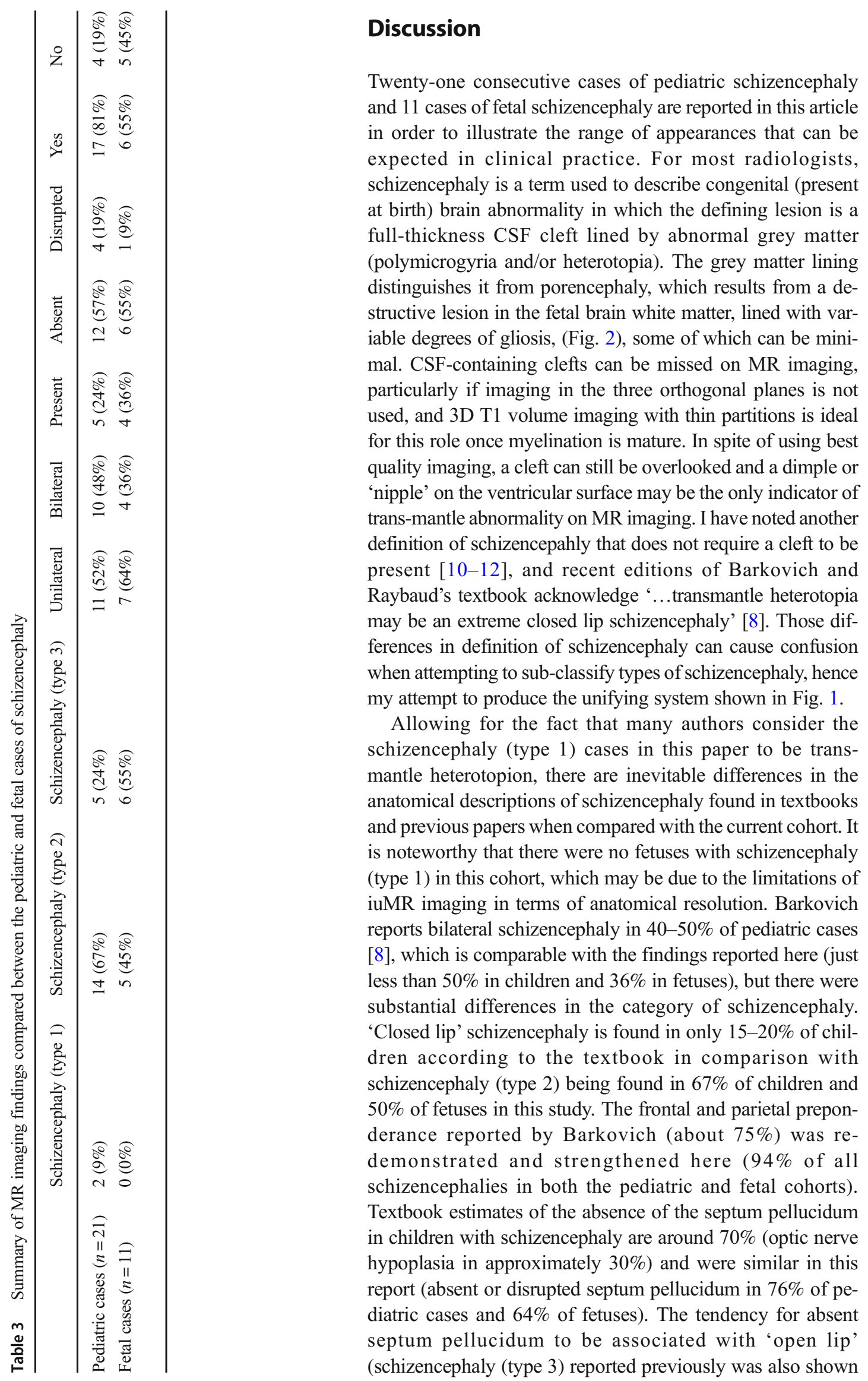


Fig. 10 Unilateral

schizencephaly (type 2) in a $21 \mathrm{gw}$ fetus. Sagittal (a) and axial $(\mathbf{b}, \mathbf{c})$ ultrafast T2-weighted images show a cleft in the right occipital lobe with opposed deep portions (arrowed on b). Subependymal heterotopia was also present (not shown). Those images are reversed to be consistent with the constructed model of the brain (d-right lateral, e - posterior and f-superior) which show the superficial part of the cleft is quite wide. There is a midline meningocoele posteriorly which is well shown on the models of the external CSF spaces $(\mathbf{g}-\mathbf{i})$


in our cases. Other brain abnormalities (not including the septum pellucidum/fornix) were found in approximately two thirds of the children which is comparable to previous reports from pediatric populations.

There are limited reports of fetal schizencephaly using iuMR imaging - for example, small case series [16] and case reports [17-19] with the largest case series to date by Nabavizadeh et al. [20] who reported 10 fetuses with schizencephaly on iuMR imaging and confirmed on postnatal imaging including eight bilateral cases. One interesting finding in that study was a morphological change in the type of cleft between the pre-natal and post-natal imaging as $47 \%$ of the 'open-lip' schizencephalies detected in utero had become 'closed lip' on post-natal imaging. Another important point was how frequently polymicrogyria was missed on iuMR imaging in that study, and this may account for the low rate of other brain abnormalities shown on iuMR in the present study (55\% compared with $81 \%$ in children).

One mechanistic explanation of the aetiology of schizencephaly arises from the work of Yakovlev and Wadsworth in 1946 [11, 12]. In their opinion, schizencephaly is due to 'failure of growth and differentiation of a circumscribed part of the cerebral wall' as quoted in Greenfield's neuropathology [21]. As such, it has its origins in the first trimester, specifically the first 2 months post-conception. Naidich [22] elaborated and refined the theory by proposing pinning of the ependymal and pia, which are anatomically very close in the first trimester (Fig. 12). The focal non-separation leads to an ependymal/pial seam that lies between the lips of the abnormal developing cleft. The ependymal/pial pinning theory may explain some features of schizencephaly (type 2 ) lesions where the lips are closely opposed, but intuitively, it seems difficult to explain the widely spaced lips and volume loss frequently present in schizencephaly (type 3 ). The proponents of this idea merely suggest that larger areas of ependyma and pia fail to separate in those cases.

There is opposition to the pinning theory in recent neuropathology texts, and Harding and Copp, writing in Greenfield's neuropathology, state '... interpretation of the apposed walls of the cleft and the bridging membrane over the defect is no longer convincing, although for obscure 

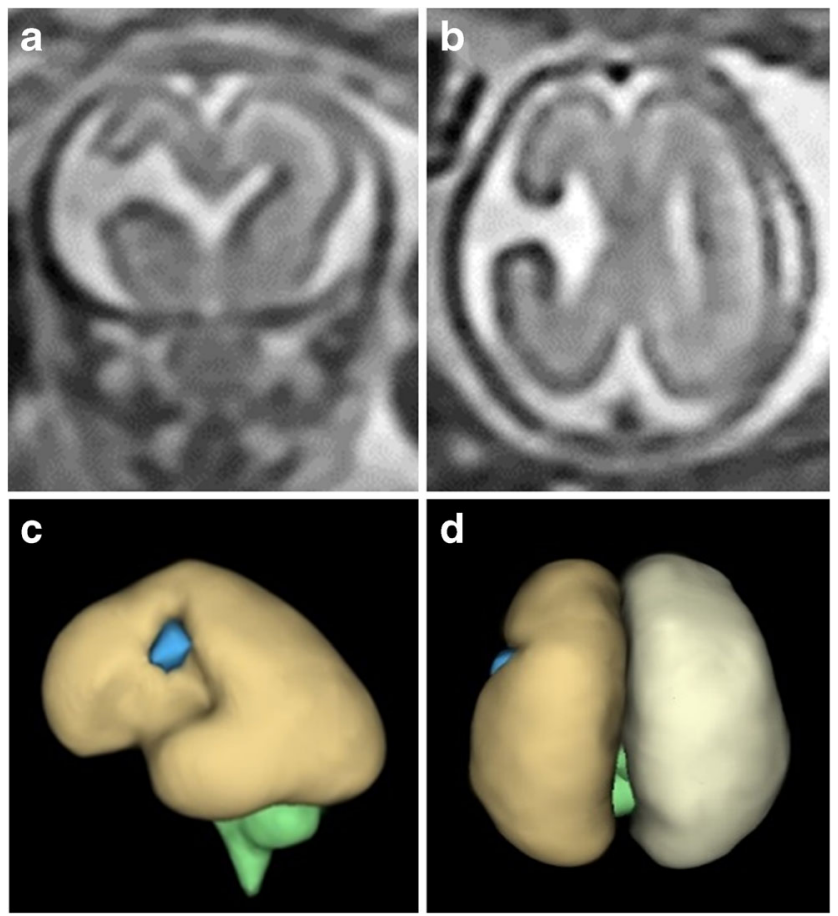

Fig. 11 Unilateral schizencephaly (type 3) in a 21 gw fetus. Coronal (a) and axial (b) ultrafast T2-weighted images show a widely spaced cleft in the right paracentral lobule. Those images are reversed to be consistent with the constructed models (c-left lateral and $\mathbf{d}$ - superior) of the brain constructed from a 3D steady-state acquisition. The septum pellucidum is absent but no other brain abnormality was shown

reasons it lingers in the radiological literature. There is now ample clinical, morphological and experimental evidence favouring a destructive origin for these lesions' [21]. Those authors go on to say that further evidence against the pinning theory is the consistent presence of abnormal cortex lining the clefts, which points to an aetiological cause in the second trimester: '...timing is suggested by the coincident polymicrogyria to be between the fourth and sixth months'. Most textbooks now consider sporadic schizencephaly (the huge majority of cases) to be the result of a destructive lesion(s): Chen, for example, states that the primary aetiology is due to 'in utero vascular insufficiency' [9]. The data emerging from iuMR imaging studies also favour destructive aetiologies in most cases. Circumstantial evidence comes from the work of Nabavizadeh et al. [20] who found that $7 / 10$ fetuses with schizencephaly had hemorrhage and/or hemosiderin deposition in the cleft or in the cerebral ventricles on iuMR imaging. The finding reported in the current paper that schizencephaly in the fetus is accompanied by a small head size in 6/11 fetuses (below the 10th centile) and in 4/11 the head size was below the 3 rd centile is relevant because the most rational explanation for the high risk of microcephaly is brain destruction. It is interesting to note that the four fetuses with the head size below the 3 rd centile all had schizencephaly (type 3), i.e. cases in which greater volume of brain injury might be predicted. Direct evidence comes from the fetus illustrated in Fig. 13, which is not from the cohort as presented but has been reported previously as web extra material [25]. That case shows the evolution of schizencephaly in a second trimester fetus with a normally formed but injured cerebral mantle. That fetus was studied because it was the result of a monochorionic pregnancy complicated by the death of the co-twin, a known risk factor for schizencephaly $[9,21]$.

Consistent with many previous descriptions, the septum pellucidum was absent in many cases of schizencephaly, although the reason for the association is not known with certainty. In some of the pediatric and fetal cases reported here, remnants of the septum pellucidum were visualised, suggesting that the structure had formed but was damaged, perhaps by raised intraventricular pressure arising from hydrocephalus secondary to intraventricular blood. It is not possible to say if this mechanism accounts for the case in which no portion of the septum pellucidum was seen.

I explained the need to distinguish between schizencephaly and porencephaly earlier, but from the discussion above, it seems likely that destructive brain parenchymal lesions are the most likely cause for most cases of schizencephaly as well as porencephaly. Why would one fetus develop schizencephaly a

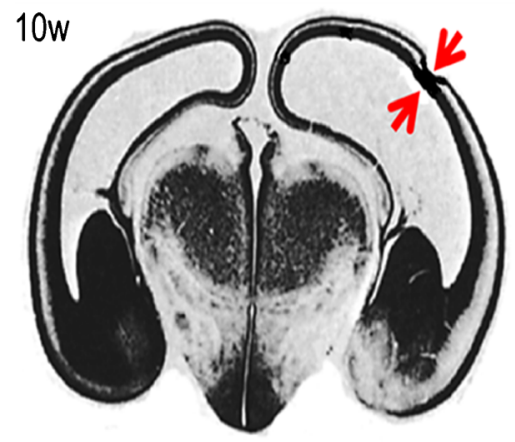

b

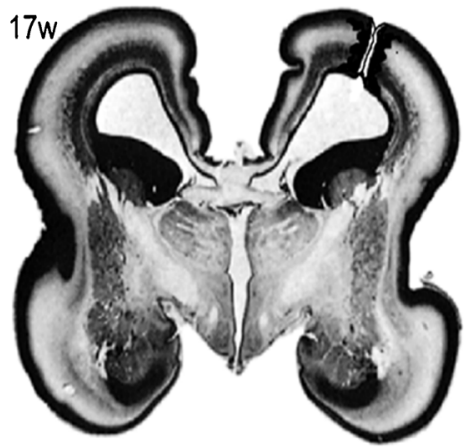

C

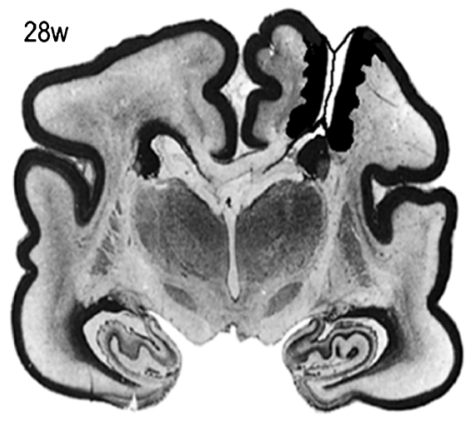

Fig. 12 Representation of the ependymal/pial pinning theory of schizencephaly. Coronal histology sections of the fetal brain at $10 \mathrm{gw}$ (a), $17 \mathrm{gw}$ (b) and $28 \mathrm{gw}$ (c) illustrate early pinning of the ependymal and pia (arrowed on a) with the development of an ependymal/pial seam. These sections have been reproduced after alteration with permission [23] 
a
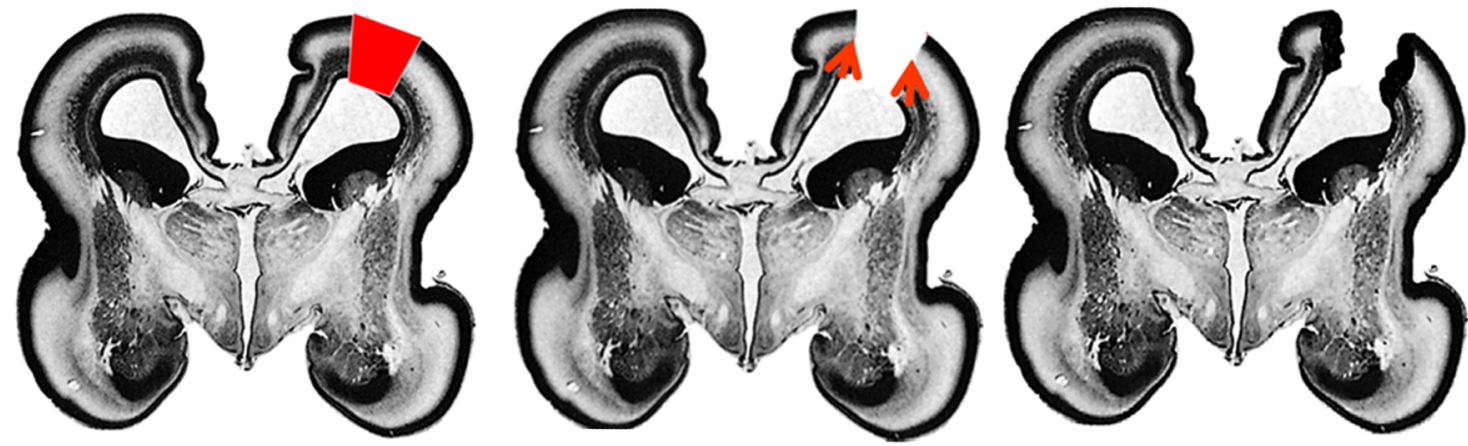

b

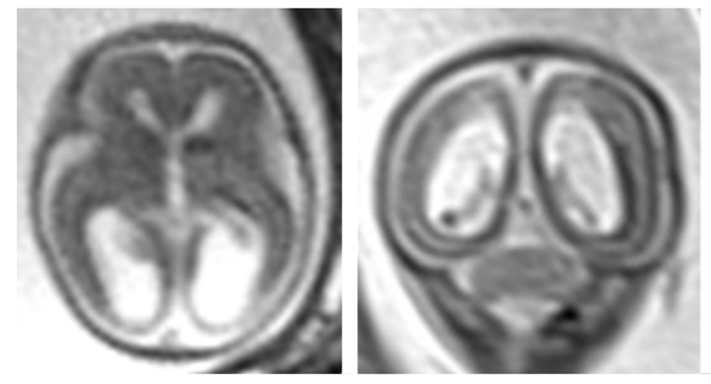

Fig. 13 Representation of the destructive theory of the formation schizencephaly. Coronal histology sections of the fetal brain at $17 \mathrm{gw}$ (a) have been reproduced after alteration with permission [24]. The red quadrilateral on figure a represents a focal, full-thickness injury to the cortical mantle and resorption of the damaged brain. Neuro-glial migration is still possible at this stage and will form the regions of polymicrogyria in the borders of the schizencephalic cleft. b iuMR images from a fetus
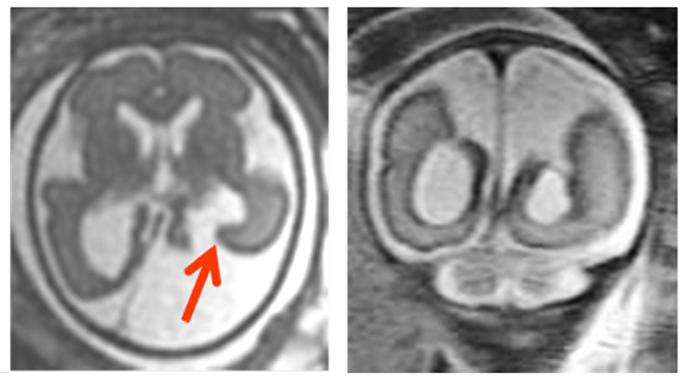

imaged on two occasions because of the history of monochorionic pregnancy and selective termination of one twin. Imaging at 21 gw shows high signal and loss of volume in the otherwise normally formed posterior portions of both hemispheres. Repeat iuMR at $27 \mathrm{gw}$ shows the development of schizencephaly (type 3 ) in the left posterior hemisphere. This case is not from our cohort but shown courtesy of Professor M. Kilby, University of Birmingham, and has been described elsewhere [25]

in normal six-layered cortex but more likely to result in what has been called 'reparative polymicrogyria'. This is a possible explanation for the association of unilateral schizencephaly (full-thickness vascular injury) and contralateral polymicrogyria (superficial vascular injury) in the same fetus as suggested in a previous work [26].

Other recognised risk factors for the development of schizencephaly include transplacental infections, classically by cytomegalovirus [21] with more recent reports of infection by the Zika virus [27]. Transplacental infection by cytomegalovirus may involve the ventricular layer (germinal matrix) where the future neurons and glia are formed and mature before migration. It is possible that in these circumstances schizencephaly may result from abnormal migration/organisation. Alternatively, cytomegalovirus infection is known to cause arteritis, which potentially could injure previously normal brain and results in schizencephaly by 'late migration' mechanism described above. Schizencephaly can also be a feature of many congenital anomaly/mental retardation conditions such as Adam-Oliver, Aicardi, Arima, Delleman, Galloway-Mowat and micro syndromes [21].

Discrete genetic causes of schizencephaly have been difficult to confirm and it is generally considered to be a nongenetic, non-familial 'sporadic' abnormality. Early reports 

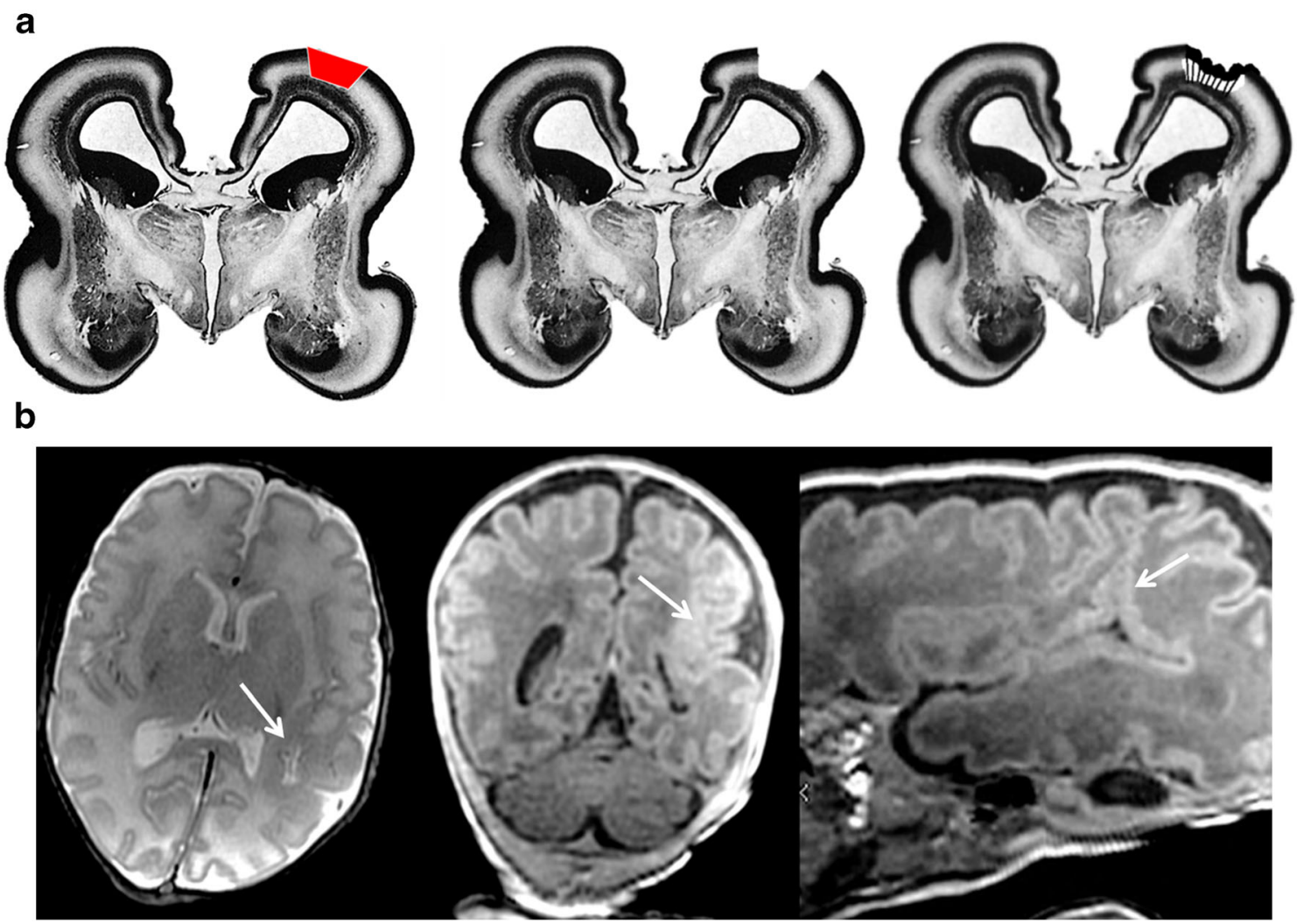

Fig. 14 Representation of the destructive theory of the formation of 'reparative' polymicrogyria. Coronal histology sections of the fetal brain at $17 \mathrm{gw}$ (a) have been reproduced after alteration with permission [24]. The red quadrilateral on a represents a focal, superficial injury to the cortical mantle, and resorption of the damaged brain is shown. Late neuro-glial migration in this case will produce polymicrogyria on the cortical surface. b iuMR images from a 9-week child which resulted from a monochorionic pregnancy complicated by twin-twin transfusion with survival of both twins. Axial T2-weighted and images from a T1 volume study and non-orthogonal along the course of the sylvian fissure show focal polymicrogyria in the abnormal posterior extension of the sylvian fissure (arrowed) linking schizencephaly to mutations in the EMX2 gene have not been borne out [24]. Two cases in our pediatric cohort did have relevant histories: one child had a known mutation of the EMX2 gene and the other had a strong family history of schizencephaly but no known genetic abnormality at the time of the MR study. The MR imaging features of those two children had striking similarities (Fig. 9) - both were microcephalic, both had bilateral schizencephaly (type 2 ) involving the paracentral lobes and both had extensive bilateral polymicrogyria and intact septum pellucidum with normally situated fornices. The presence of normal septum pellucidums in these cases is particularly noteworthy as the structure was either absent or disrupted in 16/19 (84\%) of the other children with schizencephaly.

In conclusion, I have proposed a new system for classifying schizencephaly that takes into account all definitions of the abnormality. Using that approach, I have described the appearances and associations of pediatric and fetal cases of schizencephaly from a single centre. Review of the current literature appears to favour an acquired destructive aetiology for most cases of schizencephaly, and I have proposed a mechanism to explain the cortical formation abnormalities (predominantly polymicrogyria) found consistently in and around areas of schizencephaly.

\section{Compliance with ethical standards}

Funding No funding was received for this study.

Conflict of interest The author declares that he has no conflict of interest.

Ethical approval All procedures performed in the studies involving human participants were in accordance with the ethical standards of the institutional and/or national research committee and with the 1964 Helsinki Declaration and its later amendments or comparable ethical standards.

Informed consent Informed consent was obtained from some of the individual participants included in the study as outlined in "Caseload".

Open Access This article is distributed under the terms of the Creative Commons Attribution 4.0 International License (http:// creativecommons.org/licenses/by/4.0/), which permits unrestricted use, distribution, and reproduction in any medium, provided you give appropriate credit to the original author(s) and the source, provide a link to the Creative Commons license, and indicate if changes were made. 


\section{References}

1. Curry CJ, Lammer EJ, Nelson V, Shaw GM (2005) Schizencephaly: heterogeneous etiologies in a population of 4 million California births. Am J Med Genet 137A:181-189

2. Howe DT, Rankin J, Draper ES (2012) Schizencephaly prevalence, prenatal diagnosis and clues to etiology: a register-based study. Ultrasound Obstet Gynecol 39(1):75-82

3. Brunelli S, Faiella A, Capra V, Nigro V, Simeone A, Cama A, Boncinelli E (1996) Germline mutations in the homeobox gene EMX2 in patients with severe schizencephaly. Nat Genet 12:94-96

4. Yoneda Y et al (2013) Phenotypic spectrum of COL4A1 mutations: porencephaly to schizencephaly. Ann Neurol 73:48-57

5. U H, Pineda-Alvarez DE, Uyanik G, Hu P et al (2010) Heterozygous mutations in SIX3 and SHH are associated with schizencephaly and further expand the clinical spectrum of holoprosencephaly. Hum Genet 127(5):555-561

6. Hilburger AC, Willis JK, Bouldin E, Henderson-Tilton A (1993) Familial schizencephaly. Brain Dev 15(3):234-236

7. Barkovich AJ, Norman D (1988) MR imaging of schizencephaly. Am J Roentgenol 150(6):1391-1396

8. Barkovich AJ, Raybaud CA (2012) Congenital malformations of the brain and skull. Chapters 4 and 5. In: Barkovich AJ, Raybaud CA (eds) Pediatric neuroimaging, 5th edn. Lippincott Williams and Wilkins, Philadelphia

9. Chen H (2012) Atlas of genetic diagnosis and counseling. Chen $\mathrm{H}$ (ed) Springer Publishing Company, New York City

10. Naidich TP, Griffiths PD, Rosenbloom L (2015) Central nervous system injury in utero: selected entities. Pediatr Radiol 45(3):S454 S462

11. Yakovlev PI, Wadsworth RC (1946) Schizencephalies. A study of the congenital clefts in the cerebral mantle I. Clefts with fused lips. J Neuropathol Exp Neurol 5:116-130

12. Yakovlev PI, Wadsworth RC (1946) Schizencephalies. A study of the congenital clefts in the cerebral mantle II. Clefts with hydrocephalus and lips separated. J Neuropathol Exp Neurol 5:169-206

13. Griffiths PD, Jarvis D, McQuillan H, Williams F, Paley MNJ, Armitage P (2013) 3D MR imaging of the fetal brain using a rapid steady state sequence. Br J Radiol 86(1030):20130168

14. Griffiths PD, Batty R, Reeves MJ, Connolly DJA (2009) Imaging the corpus callosum, septum pellucidum and fornix in children: normal anatomy and variations of normality. Neuroradiology 51 : 337-345

15. Griffiths PD, Batty R, Connolly DJA, Reeves MJ (2009) Effects of failed commissuration on the septum pellucidum and fornix: implications for fetal imaging. Neuroradiology 51:347-356
16. Oh KY, Kennedy AM, Frias AE, Byrne JL (2005) Fetal schizencephaly: pre- and postnatal imaging with a review of the clinical manifestations. Radiographics 25(3):647-657

17. Reddy S, Rudakemwa E, Modi M (2008) Schizencephaly on fetal MRI. SA Journal of Radiology 12(3):a562

18. Bai Y-R, Tsai P-Y, Cheng Y-C, Chang C-H, Chang F-M (2012) Prenatal diagnosis of fetal schizencephaly by ultrasonography and magnetic resonance imaging. Journal of Medical Ultrasound 20(3): $162-168$

19. Harada T, Uegaki T, Arata K, Tsunetou T, Taniguchi F, Harada T (2017) Schizencephaly and porencephaly due to fetal intracranial hemorrhage: a report of two cases. Yonago Acta Med 60(4):241245

20. Nabavizadeh SA, Zarnow D, Bilaniuk LT, Schwartz ES, Zimmerman RA, Vossough A (2014) Correlation of prenatal and postnatal MRI findings in schizencephaly. Am J Neuroradiol 35(7): $1418-1424$

21. Love S, Louis D, Ellison DW (2008) Greenfield's neuropathology. Chapter 5. In: Harding BN, Copp AJ (eds) Malformations, 8th edn. CRC, Boca Raton

22. Naidich TP (1990) Multicystic encephalomalacia (case 12). In: Weinberg PE (ed) Neuroradiology test and syllabus part 1. The American College of Radiology, Virginia, pp 307-370

23. Griffiths PD, Morris J, Larroche J-C, Reeves M (2010) In: Griffiths PD (ed) Atlas of fetal and postnatal brain MR. Mosby Elsevier, Philadelphia

24. Merello E, Swanson E, De Marco P, Akhter M, Striano P, Rossi A, Cama A, Leventer RJ, Guerrini R, Capra V, Dobyns WB (2008) No major role for the EMX2 gene in schizencephaly. Am J Med Genet 146A(9):1142-1150

25. Conte G, Righini A, Griffiths PD, Rustico M, Lanna M, Mackie FL, Pinelli L, Prefumo F, Persico N, Igra MS, Parazzini C, Doneda C, Fichera A, Ambrosi C, Kilby M, Severino M, Triulzi F, Rossi A, Skipper N (2018) Brain-injured survivors of monochorionic twin pregnancies complicated by single intrauterine death: MR findings in a multicenter study. Radiology. https://doi.org/10.1148/radiol. 2018171267

26. Barkovich AJ, Kjos BO (1992) Schizencephaly: correlation of clinical findings with MR characteristics. Am J Neuroradiol 13(1):8594

27. Honein MA, Dawson AL, Petersen EE (2017) Birth defects among fetuses and infants of US women with evidence of possible Zika virus infection during pregnancy. JAMA 317(1):59-68 